\title{
USULAN KEBIJAKAN PERSEDIAAN BAHAN BAKU DENGAN METODE LOT SIZING PADA PERUSAHAAN MANUFAKTUR GELAS PLASTIK
}

\section{Inventory Policy of Raw Materials using Lot Sizing Method in Plastic Glass Manufacturer}

\author{
Mirna Lusiani ${ }^{1 *}$, Eko Verdianto ${ }^{1}$ \\ ${ }^{1}$ Program Studi Teknik Industri, Universitas Bunda Mulia, Jl. Lodan Raya No. 2 Ancol, Jakarta Utara 14430, \\ Indonesia
}

Diterima: 11 July 2018 / Disetujui: 13 Agustus 2018

\begin{abstract}
This research was made with the aim to make production planning and inventory control in manufacturing company of plastic glass, especially for main raw material from $14 \mathrm{oz}$ plastic cup product, that is Resin-HE 2.0 and whitening using lot sizing method. Due to the fluctuating demand and the accumulation of raw materials in the warehouse, the company needs for production planning and inventory control. The lot-sizing method used in this research is Period Order Quantity (POQ), Lot For Lot (LFL) and Fixed Period Requirement (FPR) which each method have a different concept. The result by using FPR Method 3 weeks and LFL in inventory control will give the lowest inventory cost to the company that is equal to Rp. 159.400,00 for Resin-HE 2.0 and Rp. 39.600,00 for whitening.
\end{abstract}

Keywords: Inventory Control, Forecasting, Material Requirement Planning, Lot Sizing

\begin{abstract}
ABSTRAK
Penelitian ini dibuat dengan tujuan untuk membuat perencanaan produksi dan pengendalian persediaan di perusahaan manufaktur pembuatan gelas plastik, khususnya untuk bahan baku utama dari produk gelas plastik 14 oz, yaitu Resin-HE 2.0 dan bahan pemutih dengan menggunakan metode lot sizing. Di karenakan permintaan yang bersifat fluktuatif dan terjadinya penumpukan bahan baku di gudang maka perlunya perencanaan produksi dan pengendalian persediaan. Metode lot sizing yang digunakan dalam penelitian ini adalah Period Order Quantity (POQ), Lot For Lot (LFL) dan Fixed Period Requirement (FPR) yang masing-masing memiliki konsep yang berbeda. Kesimpulan dengan menggunakan Metode FPR 3 weeks dan LFL dalam pengendalian persediaan akan memberikan biaya persedian terendah kepada perusahan yaitu sebesar Rp. 159.400,00 untuk Resin-HE 2.0 dan Rp. 39.600,00 untuk bahan pemutih.
\end{abstract}

Kata Kunci: Pengendalian Persediaan, Peramalan, Material Requirement Planning, Lot Sizing

\section{PENDAHULUAN}

Persediaan merupakan salah satu unsur paling aktif dalam operasi perusahaan yang secara kontinu diperoleh, disimpan, diolah, kemudian dijual kembali pada periode mendatang (Rangkuti, 2007; Kusuma, 2009). Material Requirement Planning (MRP) dapat untuk menghasilkan informasi persediaan yang mampu digunakan untuk mendukung melakukan tindakan secara tepat dalam melakukan produksi (Wohos, Mandangi dan Walangitan, 2014).

Penelitian ini dibuat dengan tujuan untuk membuat perencanaan produksi dan pengendalian persediaan di perusahaan manufaktur pembuatan gelas plastik, khususnya untuk bahan baku utama dari produk gelas plastik $14 \mathrm{oz}$, yaitu Resin-HE 2.0 dan bahan pemutih dengan menggunakan metode lot sizing. Penelitian ini membahas karakteristik permintaan yang bersifat fluktuatif maka

*e-mail: mirna_lusiani@yahoo.com 
diperlukan perencanaan produksi dan pengendalian persediaan. Lot sizing adalah model yang menentukan waktu optimal dan tingkat produksi (Memmi dan Laaroussi, 2013). Metode lot sizing yang digunakan dalam penelitian ini adalah Period Order Quantity (POQ), Lot For Lot (LFL) dan Fixed Period Requirement (FPR) yang masing-masing memiliki konsep yang berbeda.

\section{METODOLOGI}

Penelitian ini diawali dengan mengindetifikasi masalah yang terjadi perusahaan yaitu perusahaan memiliki permasalah dalam hal pengendalian bahan baku yang mengakibatkan kelebihan bahan baku, setelah dilakukan pengumpulan data dengan mengambil data primer dan sekunder dan selanjutnya melakukan pengolahaan data dimana tahap pertama cari hasil peramalan untuk periode 2017 dengan menggunakan metode forecasting selanjutnya menyusun tabel MPS dan MRP dan terakhir menghitung biaya pengendalian dan persediaan dengan menggunakan metode lot sizing dan mencari biaya yang optimal. Keluaran rencana kebutuhan bahan baku ialah informasi yang dapat digunakan untuk melakukan pengendalian produksi (Kusuma, 2009).

\section{HASIL DAN PEMBAHASAN}

\subsection{Data}

\section{Data Permintaan Gelas Plastik $14 \mathrm{oz}$}

Data permintaan gelas plastik $14 \mathrm{oz}$ diambil dari bulan Agustus 2015 sampai April 2017 dan terdapat 90 minggu. Dalam penelitian ini data permintaan konsumen dari minggu ke 1 sampai ke 73 (Agustus 2015 - Desember 2016) di gunakan untuk meramalkan permintaan konsumen pada tahun 2017. Sedangkan data dari minggu ke 74 sampai minggu ke 90 (Januari 2017) digunakan dalam perhitungan Master production Schedule (MPS).

\section{Struktur Produk}

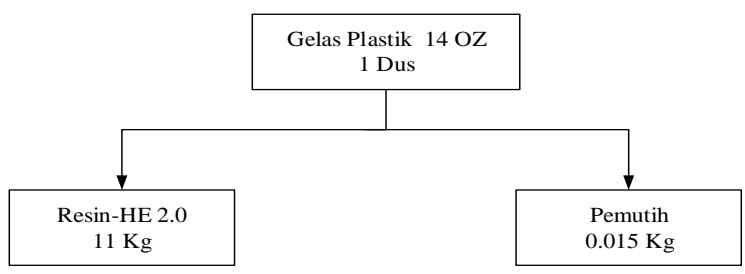

Gambar 1. Struktur Produk

\section{Bill of Material}

Tabel 1 menunjukan infromasi mengenai lead time, safety stock, on hand dan lot size dari gelas plastik $14 \mathrm{oz}$, Resin-HE 2.0 dan pemutih. Masing-masing items memiliki 1 minggu, On Hand hanya ada pada gelas plastik 14 oz. Sedangkan Resin-He 2.0 memiliki lot size sebesar $1250 \mathrm{~kg}$ dan pemutih sebesar $50 \mathrm{~kg}$, dimana penentuan lot size ini sesusai dengan minimum pembelian produk ini yaitu 1 karung yang berisi $1250 \mathrm{~kg}$ untuk Resin-HE 2.0 dan 50 $\mathrm{kg}$ untuk pemutih.

Tabel 1. Bill of Material

\begin{tabular}{lcccc}
\hline Description & $\begin{array}{c}\text { Lead } \\
\text { time }\end{array}$ & $\begin{array}{c}\text { Safety } \\
\text { Stock }\end{array}$ & $\begin{array}{c}\text { On } \\
\text { Hand }\end{array}$ & $\begin{array}{c}\text { Lot } \\
\text { Size }\end{array}$ \\
\hline Gelas & 1 & - & 1870 & - \\
Plastik 14 & week & & lot & \\
oz & & & & \\
\hline Resin-HE & 1 & - & - & 1250 \\
$\mathbf{2 . 0}$ & week & & & $\mathrm{kg}$ \\
\hline Pemutih & 1 & - & - & 50 \\
& week & & & $\mathrm{kg}$ \\
\hline
\end{tabular}

\subsection{Hasil Peramalan}

Pengukuruan tingkat error peramalan dengan melihat error terkecil dari metodemetode perhitungan error peramalan yaitu MSE dan MAPE. Metode peramalan yang digunakan pada penelitian ini adalah single moving average dan weighted moving average. Single moving average atau biasa disebut moving average menggunakan sejumlah data aktual permintaan yang baru untuk membangkitkan nilai ramalan untuk permintaan di masa yang akan datang (Gaspersz, 2005). Sementara itu, pada metode weighted moving average terlebih dahulu ditetapkan bobot dari data (Harinaldi, 2005). Setelah meramalkan dengan metode Moving Averange dan Weighted Moving Average dengan masing-masing periode yang berbedabeda, didapatkan perhitungan hasil dari MSE dan MAPE sebagai berikut.

Tabel 2. Hasil Error Peramalan MSE dan

\begin{tabular}{lcc}
\multicolumn{3}{c}{ MAPE } \\
\hline Metode & MSE & MAPE \\
\hline MA 1 & 9281.3 & $24.3 \%$ \\
MA 2 & 9802,5 & $26.2 \%$ \\
WMA 3 & 9042.3 & $23.9 \%$ \\
WMA 4 & 9641.8 & $26.5 \%$ \\
\hline
\end{tabular}


Hasil Peramalan untuk periode 2017 dengan menggunakan metode WMA 3 dapat dilihat pada Tabel 3.

Tabel 3. Hasil Peramalan 2017

\begin{tabular}{cc}
\hline Periode & Peramalan $\mathbf{2 0 1 7}$ \\
\hline $\mathbf{1}$ & 318 \\
$\mathbf{2}$ & 312 \\
$\mathbf{3}$ & 311 \\
$\mathbf{4}$ & 312 \\
$\mathbf{5}$ & 312 \\
$\mathbf{6}$ & 312 \\
$\mathbf{7}$ & 312 \\
$\mathbf{8}$ & 312 \\
$\mathbf{9}$ & 312 \\
$\mathbf{1 0}$ & 312 \\
$\mathbf{1 1}$ & 312 \\
$\mathbf{1 2}$ & 312 \\
$\mathbf{1 3}$ & 312 \\
$\mathbf{1 4}$ & 312 \\
$\mathbf{1 5}$ & 312 \\
$\mathbf{1 6}$ & 312 \\
$\mathbf{1 7}$ & 312 \\
\hline
\end{tabular}

\subsection{Material Requirement Planning}

Material Requirement Planning (MRP) adalah suatu sistem perencanaan dan penjadwalan kebutuhan material untuk produksi yang memerlukan beberapa tahapan atau dengan kata lain adalah suatu rencana produksi untuk sejumlah produk jadi di mana harus menentukan bahan baku yang dibutuhan dengan menggunakan lead time sehinga dapat ditentukan kapan dan berapa banyak pesanan untuk masing-masing komponen suatu produk yang akan dibuat (Gaspersz, 2005; Rangkuti, 2007; Kusuma, 2009). Dalam penggunaan MRP, ada beberapa teknik yang dapat digunakan, dalam penelitian ini akan menggunakan tiga teknik diantranya teknik Lot for Lot (LTL), Period Order Quantity (POQ) dan Fixed Periode Requirement (FPR). Berikut ini adalah data dan asumsi yang dipakai dalam pembuatan MRP:

1. Biaya Pemesanan Resin-HE 2.0 sebesar Rp. 17.000,00 per pemesanan

2. Biaya Pemesanan pemutih sebesar Rp. 15.000,00 per pemesanan

3. Harga Bahan baku Resin-HE 2.0 sebesar Rp. 23.000,00 per pemesanan

4. Harga Bahan baku pemutih sebesar Rp. 20.000,00 per pemesanan

5. Biaya Persediaan sebesar Rp $1.200,00$ per lot

\subsection{Perbandingan Biaya}

Tabel 4 hinnga Tabel 7 adalah gambaran mengenai biaya persediaan yang dihasilkan dari metode lot sizing yang telah digunakan sebelumnya.

Tabel 4. Total Biaya Metode Lot Sizing Bahan Baku Resin-HE 2.0

\begin{tabular}{llcrc}
\hline \multicolumn{2}{c}{ Keterangan } & $\begin{array}{c}\text { Jumlah } \\
\text { (lot) }\end{array}$ & $\begin{array}{c}\text { Biaya } \\
(\text { Rp. })\end{array}$ & $\begin{array}{c}\text { Biaya } \\
\text { Total } \\
(\text { Rp. })\end{array}$ \\
\hline POQ & Persediaan & 31 & 1.200 & \multirow{2}{*}{173.200} \\
\cline { 2 - 4 } & Pemesanan & 8 & 17.000 & \\
\hline LFL & Persediaan & 8 & 1.200 & \multirow{2}{*}{281.600} \\
\cline { 2 - 4 } & Pemesanan & 16 & 17.000 & \\
\hline FPR 3 & Persediaan & 62 & 1.200 & \multirow{1}{1}{$\mathbf{1 5 9 . 4 0 0}$} \\
weeks & Pemesanan & 5 & 17.000 & \\
\hline FPR 5 & Persediaan & 101 & 1.200 & \multirow{2}{*}{172.200} \\
\cline { 2 - 4 } weeks & Pemesanan & 3 & 17.000 & \\
\hline
\end{tabular}

Tabel 5. Total Biaya Metode Lot Sizing Bahan Baku Pemutih

\begin{tabular}{|c|c|c|c|c|}
\hline \multicolumn{2}{|c|}{ Keterangan } & $\underset{\text { (lot) }}{\text { Jumlah }}$ & $\begin{array}{c}\text { Biaya } \\
\text { (Rp.) }\end{array}$ & $\begin{array}{l}\text { Biaya } \\
\text { Total } \\
\text { (Rp.) }\end{array}$ \\
\hline \multirow[t]{2}{*}{ POQ } & Persediaan & 52 & 1.200 & \multirow{2}{*}{182.400} \\
\hline & Pemesanan & 8 & 15.000 & \\
\hline \multirow[t]{2}{*}{ LFL } & Persediaan & 8 & 1.200 & \multirow{2}{*}{39.600} \\
\hline & Pemesanan & 2 & 15.000 & \\
\hline \multirow{2}{*}{$\begin{array}{l}\text { FPR } \\
3 \\
\text { weeks }\end{array}$} & Persediaan & 33 & 1.200 & \multirow{2}{*}{114.600} \\
\hline & Pemesanan & 5 & 15.000 & \\
\hline \multirow{2}{*}{$\begin{array}{l}\text { FPR } \\
5 \\
\text { weeks }\end{array}$} & Persediaan & 18 & 1.200 & \multirow{2}{*}{66.600} \\
\hline & Pemesanan & 3 & 15.000 & \\
\hline
\end{tabular}

Tabel 6. Total Biaya Dengan Pembelian Bahan Baku Metode Lot Sizing Bahan Baku Resin-HE 2.0

\begin{tabular}{|c|c|c|c|c|}
\hline \multicolumn{2}{|c|}{ Keterangan } & $\underset{\text { (lot) }}{\text { Jumlah }}$ & $\begin{array}{l}\text { Biaya } \\
\text { (Rp.) }\end{array}$ & $\begin{array}{l}\text { Biaya } \\
\text { Total } \\
\text { (Rp.) }\end{array}$ \\
\hline \multirow[t]{3}{*}{ POQ } & Persediaan & 52 & 1.200 & \multirow{3}{*}{342.400} \\
\hline & Pemesan & 8 & 15.000 & \\
\hline & $\begin{array}{l}\text { Bahan } \\
\text { baku }\end{array}$ & 8 & 20.000 & \\
\hline \multirow[t]{3}{*}{ LFL } & Persediaan & 8 & 1.200 & \multirow{3}{*}{79.600} \\
\hline & Pemesar & 2 & & \\
\hline & $\begin{array}{l}\text { Bahan } \\
\text { Baku }\end{array}$ & 2 & 20.000 & \\
\hline \multirow{3}{*}{$\begin{array}{l}\text { FPR } \\
3 \\
\text { weeks }\end{array}$} & Persediaan & 33 & 1.200 & \multirow{3}{*}{214.600} \\
\hline & Pemesanan & 5 & 15.000 & \\
\hline & $\begin{array}{l}\text { Bahan } \\
\text { baku }\end{array}$ & 5 & 20.000 & \\
\hline \multirow{3}{*}{$\begin{array}{l}\text { FPR } \\
5 \\
\text { weeks }\end{array}$} & Persediaan & 18 & 1.200 & \multirow{3}{*}{126.600} \\
\hline & Pemesanan & 3 & 15.000 & \\
\hline & $\begin{array}{l}\text { Bahan } \\
\text { baku }\end{array}$ & 3 & 20.000 & \\
\hline
\end{tabular}


Tabel 7. Total Biaya Dengan Total Pembelian

Bahan Baku Metode Lot Sizing Bahan Baku Pemutih

\begin{tabular}{|c|c|c|c|c|}
\hline \multicolumn{2}{|c|}{ Keterangan } & $\begin{array}{c}\text { Jumlah } \\
\text { (lot) }\end{array}$ & $\begin{array}{l}\text { Biaya } \\
\text { (Rp.) }\end{array}$ & $\begin{array}{c}\text { Biaya } \\
\text { Total } \\
\text { (Rp.) }\end{array}$ \\
\hline \multirow[t]{3}{*}{ POQ } & Persediaan & 31 & 1.200 & \multirow{3}{*}{1.323 .200} \\
\hline & Pemesanan & 8 & 17.000 & \\
\hline & $\begin{array}{l}\text { Bahan } \\
\text { baku }\end{array}$ & 50 & 23.000 & \\
\hline \multirow[t]{3}{*}{ LFL } & Persediaan & 8 & 1.200 & \multirow{3}{*}{1.431 .600} \\
\hline & Pemesanan & 16 & 17.000 & \\
\hline & $\begin{array}{l}\text { Bahan } \\
\text { baku }\end{array}$ & 50 & 23.000 & \\
\hline \multirow{3}{*}{$\begin{array}{l}\text { FPR } \\
3 \\
\text { weeks }\end{array}$} & Persediaan & 62 & 1.200 & \multirow{3}{*}{1.240 .400} \\
\hline & Pemesanan & 5 & 17.000 & \\
\hline & $\begin{array}{l}\text { Bahan } \\
\text { baku }\end{array}$ & 47 & 23.000 & \\
\hline \multirow{3}{*}{$\begin{array}{l}\text { FPR } \\
5 \\
\text { weeks }\end{array}$} & Persediaan & 101 & 1.200 & \multirow{3}{*}{1.253 .200} \\
\hline & Pemesanan & 3 & 17.000 & \\
\hline & $\begin{array}{l}\text { Bahan } \\
\text { baku }\end{array}$ & 47 & 23.000 & \\
\hline
\end{tabular}

\section{SIMPULAN}

Metode peramalan yang tepat untuk di gunakan dalam memperkirakan jumlah permintaan produk gelas plastik $14 \mathrm{oz}$ pada periode 2017 adalah menggunakan metode Weighted Moving Average (WMA), khususnya WMA 3 yang menggunakan weight untuk periode -1 sebesar 0.6 , periode -2 sebesar 0.3 , dan periode -3 sebesar 0.1 serta memiliki nilai error peramalan terkecil yaitu MSE sebesar 9042.3 dan MAPE sebesar $23.9 \%$.

Hasil perencanaan persediaan dan pemesanan bahan baku menggunakan metode Material Requirement Planning (MPS) pada metode Fixed Period Requirement (FPR) 3 weeks untuk bahan baku Resin-HE 2.0 dan Lot ForLot (LFL) untuk bahan baku pemutih didapatkan total unit yang simpan selama 17 periode tahun 2017 sebesar 62 unit dengan total pemesanan dilakukan sebanyak 5 kali, sedangan bahan baku pemutih didapatkan total unit yang di simpan selama 17 periode tahun 2017 sebesar 8 unit dan total pemesanan dilakukan sebanyak 2 kali.

Metode Lot sizing yang digunakan untuk menghitung total biaya perencanaan bahan baku untuk Resin-He 2.0 dan pemutih yaitu FPR 3 weeks dan LFL dengan biaya di dapat sebesar Rp. 159.400,00 dan Rp. 39.600,00 dan untuk total biaya memperhatikan pembelian bahan baku Resin-He 2.0 dan pemutih total biaya yang di hasilkan sebesar Rp. 1.124.400,00 dan Rp. $76.600,00$.

\section{DAFTAR PUSTAKA}

Gaspersz, V. (2005) Production planning and inventory control. Jakarta: Gramedia Pustaka Utama.

Harinaldi (2005) Prinsip-prinsip statistik untuk teknik dan sains. Jakarta: Erlangga.

Kusuma, H. (2009) Manajemen produksi: perencanaan dan pengendalian produksi. Yogyakarta: Andi Publisher.

Memmi, I. C. dan Laaroussi, S. H. (2013) “A new approach for solving capacitated lot sizing and scheduling problem with sequence and period-dependent setup costs," Journal of Industrial Engineering and Management, 6(4), hal. 1027-1054. doi: 10.3926/jiem.707.

Rangkuti, F. (2007) Manajemen persediaan: aplikasi di bidang bisnis. Jakarta: Rajagrafindo Persada.

Wohos, I. P., Mandangi, R. J. M. dan Walangitan, D. R. O. (2014) "Pengendalian material proyek dengan metode material requirement planning pada pembangunan star square manado," Tekno Sipil, 12(61), hal. 25$34 . \quad$ Tersedia pada: https://ejournal.unsrat.ac.id/index.php/t ekno/article/view/6808. 